\section{R. J. M. Houmes \\ S. J. C. Verbrugge \\ E. R. Hendrik \\ B. Lachmann}

\title{
Hemodynamic effects of partial liquid ventilation with perfluorocarbon in acute lung injury
}

Abstract Objective: To assess the effect of partial liquid ventilation with perfluorocarbons on hemodynamics and gas exchange in large pigs with induced acute lung injury (ALI).

Design: Randomized, prospective, double-control, experimental study. Setting: Experimental intensive care unit of a university.

Materials: Eighteen large pigs (50 $\pm 5 \mathrm{~kg}$ body weight) with an average anterior posterior thoracic diameter of $24 \mathrm{~cm}$ and induced acute lung injury.

Interventions: All animals were surfactant depleted by lung lavage to a $P_{\mathrm{a}} \mathrm{O}_{2}$ below $100 \mathrm{mmHg}$ and randomized to receive either perflubron $(n=6)$ or saline $(n=6)$ in five intratracheal doses of $5 \mathrm{ml} / \mathrm{kg}$ at 20-min intervals, or no instillation $(n=6)$.

Measurements and results: In all animals heart rate, arterial pressures, pulmonary pressures, cardiac output and blood gases were recorded at $20-\mathrm{min}$ intervals. There was no deleterious effect on any hemodynamic parameter in the perflubron group, whereas systolic and mean pulmonary arterial pressure values showed a persistent decrease after the first $5 \mathrm{ml} / \mathrm{kg}$ of perflubron, from $48.7 \pm 14.1$ to $40.8 \pm 11.7 \mathrm{mmHg}$ and from $39.7 \pm 13.2$ to $35.2 \pm 12.0 \mathrm{mmHg}$, respectively. Perflubron resulted in a significant (ANOVA $P<0.01$ ), dose-dependent increase in $P_{\mathrm{a}} \mathrm{O}_{2}$ values from $86.3 \pm 22.4$ to a $\max -$ imum of $342.4 \pm 59.4 \mathrm{mmHg}$ at a dose of $25 \mathrm{ml} / \mathrm{kg}$; the other groups showed no significant increase in $P_{\mathrm{a}} \mathrm{O}_{2}$.

Conclusions: Tracheal instillation of perflubron in induced ALI results in a dose-dependent increase in $P_{\mathrm{a}} \mathrm{O}_{2}$ and has no deleterious effect on hemodynamic parameters.

Key words Hemodynamics - Gas exchange - Mechanical ventilation - Oxygen - Perfluorocarbon - Respiratory distress syndrome
B. Lachmann ( $\vec{J})$ - R.J.M. Houm
S.J.C. Verbrugge - E.R. Hendrik Department of Anesthesiology, Room Ee 2393, Erasmus University, Postbox 1738, NL-3000 DR Rotterdam, The Netherlands 


\section{Introduction}

In 1966 Clark and Gollan demonstrated the ability of small mammals to remain alive while breathing oxygenated perfluorocarbons (PFCs) [1]. Since then PFCs have been investigated extensively as an alternative means of respiratory support, and PFCs oxygenated outside the body have been used in the treatment of acute respiratory failure [2,3]. In 1991 Fuhrman et al. [4] demonstrated the feasibility of applying liquid ventilation in healthy animals without the need for a specialized liquid breathing system. This technique of in vivo bubble oxygenation, combining intratracheal PFC administration with conventional ventilation, brought the use of PFCs for liquid ventilation closer to clinical practice. Our group [5-7] successfully applied this technique using perflubron in rabbits with induced acute lung injury (ALI); the result was improved gas exchange, with no effect on arterial blood pressure. This perflubron (perfluorooctyl bromide; Alliance Pharmaceutical, San Diego, Calif,, USA) is a new generation of $\mathrm{PFC}$ with a low surface tension of $18.1 \mathrm{dyne} / \mathrm{cm}$, a specific gravity of $1.918 \mathrm{~g} / \mathrm{cm}^{3}$ at $25^{\circ} \mathrm{C}$, a vapor pressure of 3.6 torr at $20^{\circ} \mathrm{C}$ and of 10.5 torr at $37^{\circ} \mathrm{C}$, an oxygen solubility of $53 \mathrm{ml} / 100 \mathrm{ml}$, a $\mathrm{CO}_{2}$ solubility of $210 \mathrm{ml} / 100 \mathrm{ml}$ at $37^{\circ} \mathrm{C}$ and an atmospheric pressure of 1 .

As a result of PFC filling, pulmonary vascular compression might be present, with a resulting increase in pulmonary arterial pressure and a decrease in cardiac output [8-10]. The above-mentioned studies using PFCs to improve blood gases were performed in small animals. Based on the size of the animals used and therefore on the total weight of the PFCs used, the hydrostatic pressure of the PFCs did not result in pulmonary vascular compression. However, this effect might occur in larger animals, although no studies using partial liquid ventilation and based on this hypothesis have yet been reported. In order to reach high hydrostatic pressures, we investigated the hemodynamic effects of perflubron in large pigs in the supine position with induced ALI, whose thoracic anterior posterior diameter was about $24 \mathrm{~cm}$.

\section{Materials and methods}

\section{Animal preparation}

The protocol of this study was approved by the university's animal experimental committee. Anesthesia was induced in 18 female Yorkshire pigs (body weight $50 \pm 5 \mathrm{~kg}$ ) with ketamine $(10 \mathrm{mg} / \mathrm{kg}$ ) and midazolam $(0.5 \mathrm{mg} / \mathrm{kg})$, and was mainlained with continuous infusions of ketamine $(80 \mu \mathrm{g} / \mathrm{kg}$ per min) and midazolam $(9 \mu \mathrm{g} / \mathrm{kg}$ per min). Muscle relaxation was achieved by a continuous infusion of pancuronium bromide $(2.5 \mu \mathrm{g} / \mathrm{kg}$ per min). During the whole experimental period, all animals were in a supine position. They were tracheotomized, intubated with an $8.0-\mathrm{mm}$ endotracheal tube fitted with a Filtraflux heat-moisture exchanger with a built-in bacterial filter (ICHOR AB, Bromma, Sweden) and cannulated with a carotid artery catheter, a $5 \mathrm{~F}$ pulmonary artery catheter (SP51055H Viggo-Spectramed, Wiltshire, England) and a central venous catheter. During animal preparation, volume-controlled ventilation was provided with a Servo 300 ventilator (Siemens, Solna, Sweden) set at: frequency 20 beats $\mathrm{min}$, inspiratory time $25 \%$, pause time $10 \%$, inspiratory rise time $5 \%$, PEEP $5 \mathrm{~cm} \mathrm{H}_{2} \mathrm{O}$ and $100 \%$ oxygen. Minute ventilation was adjusted to obtain a $P_{\mathrm{a}} \mathrm{CO}_{2}$ of $40 \pm 3 \mathrm{mmHg}$. These ventilator settings were maintained during the entire study period.

All animals were surfactant depleted according to Lachmann et al. [11] by repeated lung lavage with warm saline $\left(38^{\circ} \mathrm{C}, 30 \mathrm{ml} / \mathrm{kg}\right)$ to reduce $P_{2} \mathrm{O}_{2}$ to below $100 \mathrm{mmHg}$. To perform the lavage, the animals were disconnected from the ventilator and saline was instilled via an open-bottle-tube connection to a point at which systemic pressure decreased and pulmonary arterial pressure increased significantly. The saline was removed from the lung by gravitational force, i.e. lowering the bottle. After each lavage, the animals were reconnected to the ventilator for at least $10 \mathrm{~min}$ before the next lavage was performed. After $1 \mathrm{~h}$ of ventilation following the last lung lavage, all animals were randomized to receive either perflubron $(n=6)$ or saline $(n=6)$ in five intratracheal doses of $5 \mathrm{ml} / \mathrm{kg}$ at 20 -min intervals, or to receive no instillation $(n=6)$ (control group). After the animals were disconnected from the ventilator, perflubron and saline were administered intratracheally as a bolus over a period of $10 \mathrm{~s}$; they were reconnected to the ventilator immediately thereafter.

\section{Measurements}

Systolic (SysAP), diastolic (DiaAP) and mean (MAP) arterial pressures, as well as systolic (SysPAP), diastolic (DiaPAP) and mean (MPAP) pulmonary arterial pressures, pulmonary wedge pressure (PWP) and central venous pressure (CVP), were recorded in all animals using Statham P23XL transducers (Spectramed, Oxnard, Calif.). Cardiac output (CO) was measured in triplicate using the thermodilution technique with a Sirecust 1280 monitor (Siemens, Danvers, Mass. USA), which also traced heart rate (HR) and all recorded pressures. This monitor was also used to calculate pulmonary (PVR) and systemic vascular resistance (SVR). Arterial and mixed venous samples were analyzed for blood gases, $\mathrm{pH}$ and mixed venous oxygen saturation $\left(\mathrm{SVO}_{2}\right)$ by conventional methods $(\mathrm{ABL}-$ 505 OSM-3 combination, Radiometer, Copenhagen, Denmark, set to measure swine hemoglobin). This combination was used to calcu-

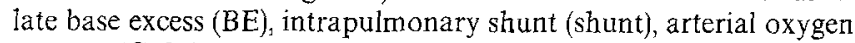
content $\left(\mathrm{C}_{\mathrm{a}} \mathrm{O}_{2}\right)$, oxygen delivery $\left(\mathrm{DO}_{2}\right)$ and anteriovenous oxygen content difference $\left(\mathrm{C}_{\mathrm{a}-\mathrm{v}} \mathrm{O}_{2}\right)$. All measurements were recorded prior to lung lavage and subsequently at 20 -min intervals (at $20 \mathrm{~min}$ after each dose in the treated groups in order to reach a steady state). At the end of the study period, all animals were killed with an intracardiac overdose of $\mathrm{KCl}$.

\section{Statistical analysis}

All statistical analyses on recorded data were performed using the Instat 2.0 biostatistics package (GraphPad Software, San Diego, Calif., USA). All intra-group comparisons were made with ANOVA repeated measures. If ANOVA resulted in a $P<0.05$, a Dunnett 
post-test was performed. This post-test used the post-lavage data (dose $=0 \mathrm{ml} / \mathrm{kg}$ body weight) as control. A $P$ value of 0.05 was regarded as significant. All data are reported as mean values \pm standard deviation (SD).

\section{Results}

All animals were comparable with regard to body weight and thoracic diameter. Before and after lung lavage, all were also comparable with regard to blood gases and hemodynamic data $(P>0.05$, ANOVA). An average of $4 \pm 1$ lavages was needed to obtain a $P_{\mathrm{a}} \mathrm{O}_{2}$ below $100 \mathrm{mmHg}$ after resumption of ventilation. Although $\mathrm{CO}$ before and after lavage was slightly lower in the control group than in the two treated groups, this difference was not statistically significant. All animals survived the study period. Table 1 gives all the data on the hemodynamic parameters measured and calculated during the study; Table 2 gives all the data on the recorded gas exchange parameters.

Hemodynamics (Table 1)

\section{Control group}

After lung lavage, HR in the control group showed a significant increase from $113.2 \pm 30.3$ to $123.7 \pm 33.6$ beats/min $(P<0.05)$ and SysAP values increased from $121.0 \pm 27.6$ to $139.3 \pm 14.0 \mathrm{mmHg}$; there was no significant change in DiaAP, MAP or CO, whereas $\mathrm{CVP}$ values decreased from $8.5 \pm 3.1$ to $6.8 \pm 3.5 \mathrm{mmHg}(P<0.05)$. There was no significant change in PWP, PVR, SVR or pulmonary arterial pressures.

\section{Saline group}

Following the lavage procedure and subsequent saline instillation, HR increased from $104.2 \pm 7.5$ to $153.8 \pm 28.7$ beats $/ \min (P<0.01)$. There was no significant change in arterial pressures and SysPAP, whereas DiaPAP and MPAP values increased from $30.5 \pm 8.4$ to $38.7 \pm 7.3 \mathrm{mmHg}$ and from $37.7 \pm 6.9$ to $46.7 \pm 5.6 \mathrm{mmHg}$, respectively. $\mathrm{CO}$ values increased from $5.0 \pm 0.9$ to $7.3 \pm 1.3 \mathrm{l} / \mathrm{min}(P<0.01)$; CVP values, from $5.7 \pm 2.9$ to $9.2 \pm 3.3 \mathrm{mmHg}(P<0.01)$; and PWP values, from $10.7 \pm 4.7$ to $13.0 \pm 4.6 \mathrm{mmHg}$ $(P<0.01)$. There was no significant change in PVR, whereas SVR values decreased from $1995.8 \pm 324$ to $1346.3 \pm 261$ dynes $\cdot \mathrm{s} / \mathrm{cm}^{5}(P<0.01)$.

\section{Perflubron group}

Following lung lavage and perflubron treatment, there were no statistically significant changes in HR, arterial pressures, CO, CVP, PVR or SVR. SysPAP and MPAP values decreased from $48.7 \pm 14.1$ to $40.8 \pm 11.7 \mathrm{mmHg}(P<0.01)$ and from $39.7 \pm 13.2$ to $34.8 \pm 11.3 \mathrm{mmHg}(P<0.01)$, respectively. There was an increase in PWP values from $11.2 \pm 4.4$ to $15.2 \pm 3.8 \mathrm{mmHg}$, resulting in a statistically significant difference $(P<0.05)$ at the $25 \mathrm{ml} / \mathrm{kg}$ body weight dose.

Gas exchange parameters (Table 2)

\section{Control group}

In the post-lavage period, there were no significant changes in $P_{\mathrm{a}} \mathrm{O}_{2}$ or shunt; $P_{\mathrm{CO}}$ increased from $52.4 \pm 10.7$ to $62.0 \pm 16.9 \mathrm{mmHg} \quad(P<0.01)$, with a subsequent decrease in $\mathrm{pH}$ from $7.34 \pm 0.05$ to $7.28 \pm 0.09(P<0.01)$; and there was no statistically significant change in $\mathrm{BE} . \mathrm{SVO}_{2}$ values increased over time from $48.8 \pm 18.4$ to $51.9 \pm 13.3 \%(P<0.05)$. Analysis of calculated gas exchange parameters $\mathrm{C}_{\mathrm{a}} \mathrm{O}_{2}$, $\mathrm{D}_{\mathrm{a}} \mathrm{O}_{2}$ and $\mathrm{C}_{\mathrm{a}-\mathrm{v}} \mathrm{O}_{2}$ showed no statistically significant changes.

\section{Saline group}

Saline instillation resulted in a statistically significant and immediate dose-dependent deterioration of all gas exchange parameters $\left(P_{\mathrm{a}} \mathrm{O}_{2}, \mathrm{PCO}_{2}, \mathrm{pH}, \mathrm{BE}, \mathrm{SVO}_{2}\right.$, shunt, $\mathrm{C}_{\mathrm{a}} \mathrm{O}_{2}, \mathrm{D}_{\mathrm{a}} \mathrm{O}_{2}$ and $\mathrm{C}_{\mathrm{a}-\mathrm{v}} \mathrm{O}_{2}$ ).

\section{Perflubron group}

Perflubron treatment resulted in a dose-dependent improvement in the measured gas exchange parameters. $P_{\mathrm{a}} \mathrm{O}_{2}$ values increased from $86.5 \pm 22.4$ to $342.1 \pm 59.4 \mathrm{mmHg}(P<0.01)$; at doses of 15,20 and $25 \mathrm{ml} / \mathrm{kg}$, this increase was significantly different from the immediate post-lavage $P_{\mathrm{a}} \mathrm{O}_{2}$ values. $\mathrm{PCO}_{2}$ values decreased from $60.4 \pm 19.9$ to $53.3 \pm 15.7 \mathrm{mmHg}$ $(P<0.01)$ and $\mathrm{pH}$ increased from $7.28 \pm 0.13$ to $7.34 \pm 0.11(P<0.01)$. BE values increased towards pre-lavage (healthy) values (i.e. $3.9 \pm 0.9 \mathrm{mmol} / \mathrm{l}$ ), from $-0.5 \pm 2.8$ to $1.5 \pm 2.5 \mathrm{mmol} / \mathrm{1} \quad(P<0.01)$. $\mathrm{SVO}_{2}$ values increased rapidly from $45.6 \pm 8.5$ to $59.5 \pm 16.4 \% \quad(P<0.01)$, whereas shunt values decreased from $36.6 \pm 17.8$ to $14.2 \pm 3.1 \%$ $(P<0.01) . \mathrm{C}_{\mathrm{a}} \mathrm{O}_{2}$ values increased from $11.7 \pm 1.5$ to 


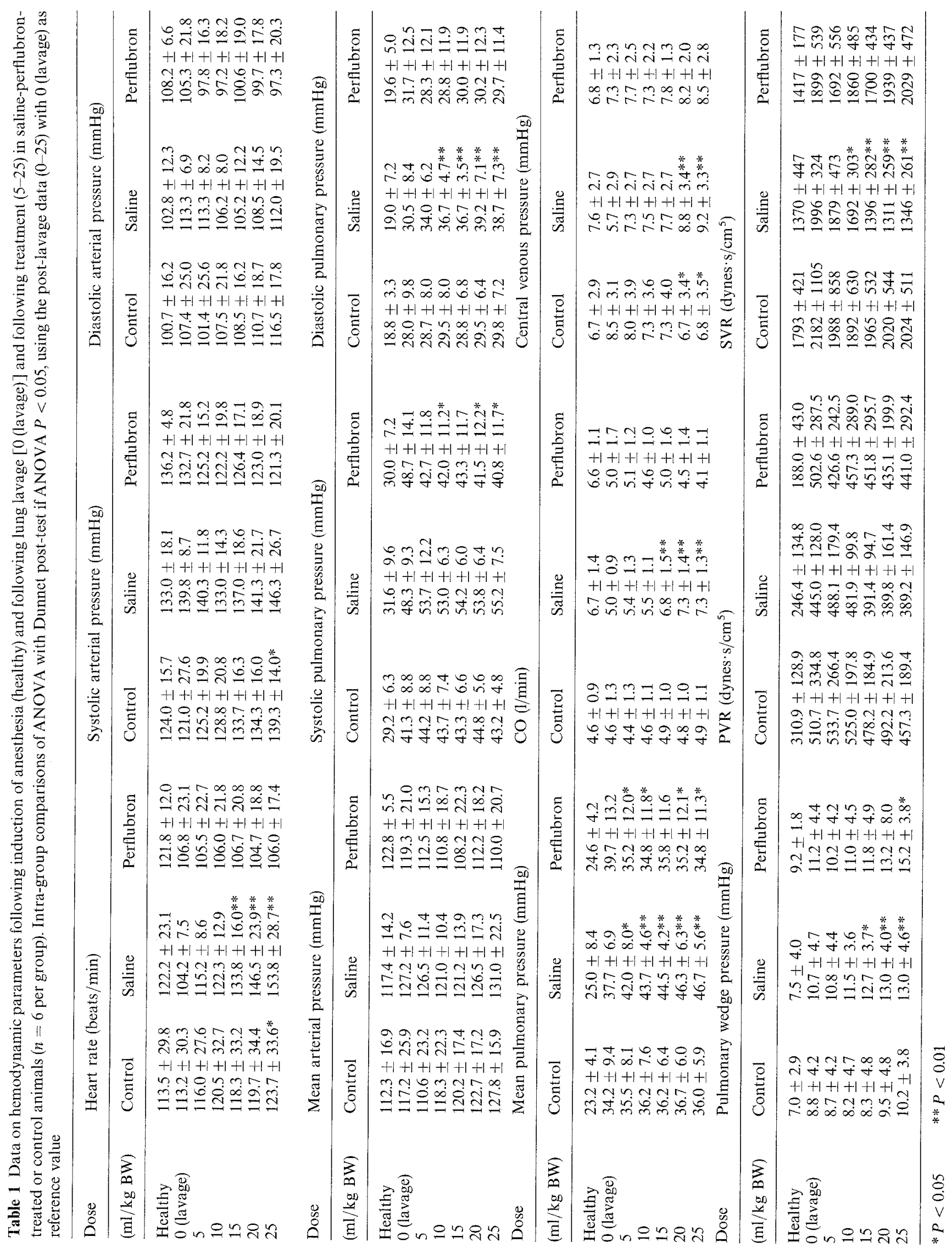




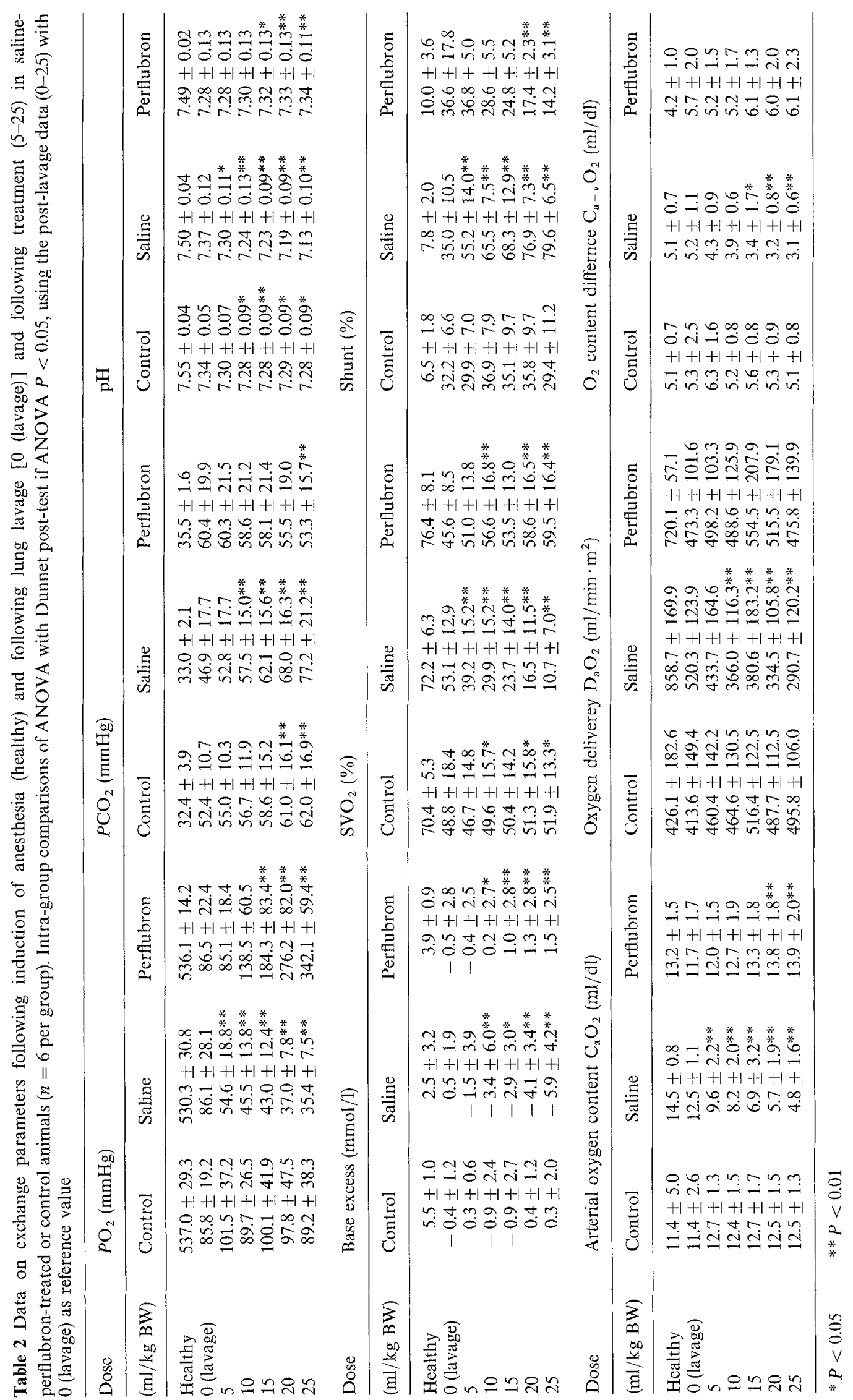


$13.9 \pm 2.0 \mathrm{ml} / \mathrm{dl}(P<0.01)$, whereas there were no significant changes in $\mathrm{D}_{\mathrm{a}} \mathrm{O}_{2}$ or $\mathrm{C}_{\mathrm{a}-\mathrm{v}} \mathrm{O}_{2}$.

\section{Discussion}

Since the introduction of partial liquid ventilation, only reports describing the influence of PFCs on gas exchange in small animals have appeared in the literature $[5-7,12,13]$. The results of the present study show that the use of perflubron for partial liquid ventilation in induced ALI is an easy and effective therapy for improving gas exchange in large animals, as well. Additionally, this study shows that the use of perflubron did not result in any deleterious effect on the hemodynamic parameters measured.

In the present study, in order to achieve high hydrostatic pressures, we used pigs with an average thoracic anterior-posterior diameter of $24 \mathrm{~cm}$; in a totally PFCfilled lung, this would result in an average hydrostatic pressure of $46 \mathrm{cmH}_{2} \mathrm{O}$ at the basal lung regions, as the specific gravity of perflubron is $1.918 \mathrm{~g} / \mathrm{cm}^{3}$ at $25^{\circ} \mathrm{C}$.

Perflubron instillation in these animals shows that the use of partial liquid ventilation does not result in statistically significant changes in arterial pressures, CO, PVR or SVR. Systolic and mean pulmonary arterial pressures showed a decrease after administration of only $5 \mathrm{ml} / \mathrm{kg}$ body weight perflubron and remained low throughout the study period. PWP showed a dose-dependent increase in both the perflubron- and saline-treated groups. This may be attributed to the weight of the fluid-filled lung on the heart, resulting in a reduction of the diastolic filling phase. On the other hand, a fluid-filled lung might interfere with zone 3 conditions and therefore result in erroneous PWP readings.

In the perflubron group, there was no significant dose-dependent effect on PVR. This may be attributed in part to a decrease in MPAP and to the small decrease in $\mathrm{CO}$, combined with the observed increase in PWP. However, an actual change in PVR cannot be excluded, and we speculate that this could result from the following interactions: with increasing doses of perflubron, oxygenation improves, resulting in a dosedependent decrease in hypoxic vasoconstriction; this, in turn, results in a decrease in PVR. However, this decrease in PVR might be counteracted by a hydrostatic vascular compression due to the instillation of perflubron (because of its high specific gravity), leading to an increase in PVR. The amount of increase in PVR due to hydrostatic vascular compression might be smaller than expected, as in vivo bubble oxygenation in partial liquid ventilation, together with the fact that the lung is only partially fluid filled, prevents the formation of uninterrupted vertical fluid columns. Therefore, the actual hydrostatic pressure will be lower than expected, as a surface pressure is dependent on the height of the fluid column above it. This situation is different from that during total liquid ventilation, where the lung is totally filled with fluid. A few studies reported hemodynamic compromise during total liquid ventilation. The authors of these studies attributed this result to the filling of the lung with high-density PFCs $[2,3]$. The observed hemodynamic compromise in these total liquid ventilation studies is speculated to result from pulmonary vascular compression, which is caused by an increase in the alveolar hydrostatic pressure gradient [9], and/or through an impairment of $\mathrm{CO}$ via a decrease in right ventricular preload combined with an increase in right ventricular afterload [10]. One report showed that this hemodynamic compromise could be corrected by adequate intravascular fluid administration [10].

The induced-ALI model used in the present study results in a decrease in arterial oxygenation as a result of a surfactant-deficiency-induced end-expiratory collapse, and is comparable to the changes found in respiratory distress syndrome (RDS) [14-16]. The results of this study confirm the positive effect of perflubron on gas exchange, as arterial oxygenation showed a significant dose-dependent increase and carbon dioxide elimination was significantly improved by perflubron treatment. This positive effect of partial liquid ventilation might be mediated through the prevention of endexpiratory collapse by the physical presence of PFC in the alveolus. Due to the high transport capabilities for $\mathrm{O}_{2}$ and $\mathrm{CO}_{2}$, PFCs can maintain gas exchange through in vivo bubble oxygenation [4]. This high transport capability results in a high dissolved volume of $\mathrm{O}_{2}$ that continues to oxygenate the blood during the expiratory period, which in a normal pattern of breathing is twothirds of the respiratory cycle.

The fact that the study was performed in large animals and used a post-lavage waiting period of $1 \mathrm{~h}$ makes this model comparable to other models of ALI and shows that the improvement in gas exchange can also occur in flooded alveoli [17]. In the perflubrontreated group, $\mathrm{SVO}_{2}$ showed a dose-dependent improvement, whereas $\mathrm{CO}, \mathrm{DO}_{2}$ and $\mathrm{C}_{\mathrm{a}-\mathrm{v}} \mathrm{O}_{2}$ showed no statistically significant improvement. This could indicate a better balance of oxygen demand and availability, which is also indicated by the improvement in BE (see below). However, firm conclusions can not be drawn from these data. The same effect was observed in the control group, in which $\mathrm{SVO}_{2}$ improved over time.

In contrast to the saline and control groups, the arterial $\mathrm{pH}$ in the perflubron-treated group showed 
a statistically significant, dose-dependent increase towards physiological values, as did the arterial BE, indicating that the metabolic acidosis observed by others [6] did not occur in the present study. The fact that $\mathrm{pH}$ and $\mathrm{BE}$ improved in the perflubron group could be speculated to result from the adequate hemodynamic status (i.e. stable $\mathrm{CO}$ and $\mathrm{DO}_{2}$ ), preventing the development of lactic acidosis.

Based on the promising results of the present study, further investigations should be directed towards clinical outcome as well as towards the financial benefits of this easy-to-administer and highly effective type of ventilatory support.
In conclusion, this study demonstrates that (1) the use of perflubron for partial liquid ventilation does not lead to hemodynamic depression; (2) perflubron partial liquid ventilation is an efficacious method for optimizing gas exchange in induced ALI; and (3) the use of perflubron does not result in metabolic acidoses, but improves $\mathrm{pH}$ towards physiological values.

Acknowledgements We thank Mrs Laraine Visser-Isles for English language editing and Mr. Ari $\mathrm{Kok}^{\dagger}$ for his technical assistance. This research was supported in part by the International Foundation for Clinically Oriented Research and by the Alliance Pharmaceutical Corporation, San Diego, Calif., USA.

\section{References}

1. Clark LC, Gollan F (1966) Survival of mammals breathing organic liquids equilibrated with oxygen at atmospheric pressure. Science 152: 1755-1756

2. Wolfson MR, Greenspan JS, Deoras KS, Rubenstein SD, Shaffer TH (1992) Comparison of gas and liquid ventilation: clinical, physiological, and histological correlates. J Appl Physiol 72: 1024-1031

3. Greenspan JS, Wolfson MR, Rubenstein D, Shaffer TH (1990) Liquid ventilation of human preterm neonates. J Pediatr 117: $106-111$

4. Fuhrman BP, Paczan P, Defrancisis M (1991) Perfluorocarbon-associated gas exchange. Crit Care Med 19: $712-722$

5. Tütüncü AS, Faithfull NS, Lachmann B (1993) Intratracheal perfluorocarbon administration combined with artificial ventilation in experimental respiratory distress syndrome: dose-dependent improvement of gas exchange. Crit Care Med 21: 962-969

6. Tütüncï AS, Faithfull NS, Lachmann B (1993) Comparison of ventilatory support with intratracheal perfluorocarbon administration and conventional mechanical ventilation in animals with acute respiratory failure. Am Rev Respir Dis 148: 785-792
7. Tütüncü AS, Akpir K, Mulder P, Erdmann W, Lachmann B (1993) Intratracheal perfluorocarbon administration as an aid in the ventilatory management of respiratory distress syndrome. Anesthesiology 79: 1083-1093

8. Lowe CA, Tuma RF, Sivieri EM, Shaffer TH (1979) Liquid ventilation: cardiovascular adjustments with secondary hyperlactatemia and acidosis. J Appl Physiol 47: 1051-1057

9. Lowe CA, Shaffer TH (1986) Pulmonary vascular resistance in the fluorocarbonfilled lung. J Appl Physiol 60: 154-159

10. Curtis SE, Fuhrman BP, Howland DF, DeFrancisis M, Motoyama EK (1991) Cardiac output during liquid (perfluorocarbon) breathing in newbron piglets. Crit Care Med 19: 225-230

11. Lachmann B, Robertson B, Vogel J (1980) In vivo lung lavage as an experimental model of the respiratory distress syndrome. Acta Anaesth Scand 24: 231-236

12. Lowe Leach C, Fuhrman BP, Morin FC, Rath MR (1993) Perfluorocarbonassociated gas exchange (partial liquid ventilation) in respiratory distress syndrome: a prospective, randomized, controlled study. Crit Care Med 21: $1270-1278$
13. Nesti FD, Fuhrman BP, Steinhorn DM, Papo MC, Hernan LJ, Duffy LC, Fisher JE, Leach CL, Paczan PR, Burak BA (1994) Perfluorocarbon-associated gas exchange in gastric aspiration. Crit Care Med 22: 1445-1452

14. Petty TL, Reiss OK, Paul GW, Silvers GW, Elkins ND (1977) Characteristics of pulmonary surfactant in adult respiratory distress syndrome associated with trauma and shock. Am Rev Respir Dis 115: 531-536

15. Hallman M, Spragg $R$, Harell JH, Moser KM, Gluck L (1982) Evidence of lung surfactant abnormality in respiratory failure. J Clin Invest 70: 673-683

16. Avery ME, Mead J (1959) Surface properties in relation to atelectasis and hyaline membrane disease. Am J Dis Child 97: 517-523

17. Nielsen JB, Sjöstrand UH, Edgren EL, Lichtwarck-Ashoff $M$, Svensson BA (1991) An experimental study of different ventilatory modes in piglets in severe respiratory distress induced by surfactant depletion. Intensive Care Med 17: 225-233 